\title{
OS LIMITES AO COMÉRCIO DE PRODUTOS FARMACÊUTICOS
}

The limits to the trade of pharmaceutical products

${ }^{1}$ Instituto Brasileiro de Advocacia Pública. Curitiba/PR, Brasil.

Correspondência: Luiz Henrique Sormani Barbugiani. E-mail: henrluiz@yahoo.com.br.

Recebido em: 16/03/2014. Aprovado em: 31/03/2014. 


\section{RESUMO}

O exercício do poder de polícia sanitário é crucial para propiciar a salvaguarda da saúde coletiva da população. O princípio da legalidade - na acepção de que tudo o que não é proibido é permitido - não se aplica ao direito sanitário enquanto instrumento da fiscalização sanitária que, ao defender o interesse público, utiliza-se de diversos princípios que suplantam a questão da mera previsão legal, buscando uma real defesa da sociedade, pois o bem jurídico tutelado possui maior envergadura do que eventuais direitos individuais dos estabelecimentos submetidos à fiscalização. Nessa seara, as normas sanitárias devem ser interpretadas em consonância com os conhecimentos técnicos das profissões relacionadas à saúde, não se restringindo à aplicação singela do conteúdo abstrato da lei.

\section{Palavras-chave}

Comércio de Produtos Farmacêuticos; Estabelecimentos Farmacêuticos; Fiscalização Sanitária; Saúde Pública.

\section{ABSTRACT}

The implementation of health policies is essential for ensuring the protection of public health. The principle of legality - in the sense that everything that is not forbidden is allowed - does not apply to health laws as instruments of health assessment that, by defending the public interests, adopt many principles that supersede the question of mere legal provision, aiming at the real protection of society. This is because the safeguarded legal asset has a larger impact than the individual rights of the facilities subjected to inspection. In this sense, health standards should be interpreted in line with the technical knowledge of health care professions and should not be restricted to the simple application of the abstract content of the law.

\section{Keywords}

Health Inspection; Pharmaceutical Facilities; Public Health;Trade of Pharmaceuticals. 


\section{DECISÃO}

Apelação n. 0034260-27.2012.8.26.0053

Julgamento: 13 de agosto de 2013

Relator: Castilho Barbosa

Órgão julgador: Tribunal de Justiça de São Paulo

Ementa: Apelação Cível Mandado de Segurança Pretensão a livre comercialização de produtos cosméticos, assim como a sua manipulação, exposição, estoque mínimo, sem a necessidade de registro no Ministério da Saúde. Inconformismo. Inadmissibilidade. Tratando de disposições referentes ao comércio farmacêutico, não se pode estender a interpretação de correlatos a produtos como outros que não assim considerados (os considerados estritamente farmacêuticos). Aplicação do Artigo $4^{\circ}$ da Lei n. 5.991/1973. Recurso improvido.

\section{Síntese dos elementos apresentados pelo acórdão}

O acórdão referente à Apelação n. 0034260-27.2012.8.26.0053, julgado em 13 de agosto de 2013, oriundo do Tribunal de Justiça de São Paulo, ao aplicar o Artigo $4^{\circ}$ da Lei n. 5.991/1973 ${ }^{1}$, manteve a sentença proferida em primeiro grau de jurisdição.

A decisão do juízo de primeira instância, ao analisar o mandado de segurança ajuizado por diversas drogarias em litisconsórcio, segundo o relatório do acórdão, "entendeu que a Anvisa [Agência Nacional de Vigilância Sanitária], como agência reguladora, teria competência para executar ações de controle e fiscalização da prestação de serviço de interesse público, uma vez que investida pelo poder de polícia”.

No corpo do acórdão, constata-se que os autores da ação mandamental e, sequencialmente, apelantes "objetivam a livre comercialização de produtos cosméticos, assim como a sua manipulação, exposição, estoque mínimo", tudo "sem a necessidade de registro no Ministério da Saúde, por entender indevida a exigência da autoridade impetrada".

$\mathrm{O}$ argumento principal utilizado pelos recorrentes, e posteriormente rechaçado pela sentença, foi a inexistência de previsão legal expressa para as exigências formuladas pela fiscalização sanitária, conforme se depreende de trecho da decisão de primeiro grau reproduzido no acórdão:

${ }^{1}$ BRASIL. Lei n. 5.991, de 17 de dezembro de 1973. Dispõe sobre o Controle Sanitário do Comércio de Drogas, Medicamentos, Insumos Farmacêuticos e Correlatos, e dá outras Providências. Disponível em: <http:// www.planalto.gov.br/ccivil_03/leis/L5991.htm>. Acesso em 30 set. 2014. 
se a lei que rege a matéria silencia acerca da manipulação de cosméticos por drogarias e farmácias sem a devida prescrição médica ou ordem prévia de manipulação de farmacêutico, isto não significa que ela autorize a livre comercialização e manipulação de tais produtos sem qualquer controle.

No acórdão reportou-se ao posicionamento jurisprudencial dominante e aos elementos destacados pelo Ministério Público - que se manifestou acerca das intercorrências que podem atingir a disponibilização irrestrita de produtos sem a devida fiscalização ou registro sanitário, o que, por sua vez, pode ocasionar, em diversas circunstâncias, males inimagináveis à saúde, motivo pelo qual a decisão foi abalizadamente proferida.

O órgão do Ministério Público, no caso versado nos autos, asseverou a legitimidade da exigência de prescrição médica ou de farmacêutico para eventual manipulação de cosmético - mesmo na ausência de determinação legal expressa - como medida de proteção à saúde coletiva, sob o fundamento de que "são inúmeros os casos de pessoas que, utilizando produtos cosméticos, passam a desenvolver reações alérgicas, irritação na pele e no couro cabeludo, tudo em decorrência da química presente nestes produtos".

O relator do acórdão assinalou que, em situação assemelhada, o órgão colegiado ( ${ }^{\text {a }}$ Câmara de Direito Público) já se manifestara pela viabilidade da autuação e fiscalização sanitária na hipótese de comercialização de produtos não especificados na legislação de regência, como correlatos, mais precisamente na Apelação n. 188.486-5/8, usando, portanto, dos fundamentos já externados naquela ocasião para embasar a denegação da ordem nessa ação judicial que se comenta.

Da mesma forma, no outro caso referenciado, o Ministério Público opinou pela impossibilidade de considerar "sorvetes, bolachas e quejandos" como produtos correlatos autorizados pela legislação para comercialização em farmácias e drogarias, acrescentando que, ainda que pudessem ser inseridos no conceito de correlatos, somente poderiam ser disponibilizados se houvesse o devido registro no Ministério da Saúde, em decorrência das exigências previstas na Lei n. 5.991/1973, Lei n. 6.360/1976², Decreto n. 79.094/1977³, dentre outras disposições legais e regulamentares.

O representante do Ministério Público, na oportunidade, ressaltou que o registro deriva de "uma forma de garantir a qualidade dos produtos comercializados nos estabelecimentos farmacêuticos".

\footnotetext{
2BRASIL. Lei n. 6.360, de 23 de setembro de 1976. Dispõe sobre a Vigilância Sanitária a que ficam sujeitos os Medicamentos, as Drogas, os Insumos Farmacêuticos e Correlatos, Cosméticos, Saneantes e Outros Produtos, e dá outras Providências. Disponível em: <http://www.planalto.gov.br/ccivil_03/leis/16360.htm>. Acesso em: 30 set. 2014.

${ }^{3}$ NOTA DO EDITOR. Este dispositivo foi revogado pelo Decreto n. 8.077, de 14 de agosto de 2013. Regulamenta as condições para o funcionamento de empresas sujeitas ao licenciamento sanitário, e o registro, controle e monitoramento, no âmbito da vigilância sanitária, dos produtos de que trata a Lei n. 6.360, de 23 de setembro de 1976, e dá outras providências. Disponível em: <http://www.planalto.gov.br/ccivil_03/_ Ato2011-2014/2013/Decreto/D8077.htm\#art25>. Acesso em 30 set. 2014.
} 
$\mathrm{O}$ acórdão anterior fundamentava-se, ainda, em posição adotada pela $5^{\mathrm{a}}$ Câmara de Direito Público, na Apelação Cível n. 277.364-2, que refutara a ponderação externada pelos recorrentes, no sentido de que não haveria proibição legal para a comercialização dos produtos que se pretendia, nos seguintes termos:

A tese defendida no apelo de ausência de vedação expressa na lei é pouco convincente, pois sempre causará espécie a venda de produtos estranhos em estabelecimento com finalidade restrita à saúde humana, eis que a ampliação do objetivo para permitir a venda de mercadorias úteis e necessárias acabaria por descaracterizar as empresas de forma geral, criando situação de autêntica balbúrdia.

\section{Considerações sobre 0 acórdão}

A questão da fiscalização sanitária é de extrema relevância para a prevenção, restauração e conservação da saúde pública, atividades englobadas no conteúdo dos conceitos de preservação, prevenção e proteção presentes na Lei n. 8.080/19904.

O princípio in dubio pro salute associado ao princípio da precaução pode sintetizar o conteúdo essencial da decisão proferida recentemente, em agosto de 2013, pelo Tribunal de Justiça de São Paulo.

In dubio, segundo De Plácido e Silva, é considerado como uma "locução, que se traduz em caso de dúvida, empregada inicialmente em alguns aforismos jurídicos, em que se institui a regra a ser estabelecida, quando a indecisão possa fazer paralisar a solução do caso"s (destaque no original).

Salute, por sua vez, é um termo autoexplicativo e, em conjugação com o designativo in dubio supracitado, enseja o princípio in dubio pro salute, que consiste em preservar e resguardar a saúde pública se, na análise da norma editada, mais de uma interpretação puder ser inferida. Ou seja, esse princípio exige que se aplique a norma conforme a interpretação que, de maneira mais ampla, proteja a saúde da coletividade.

Dentro dessa concepção, pondera-se que tal princípio não se restringe a regras de interpretação da norma, englobando necessariamente o exercício do poder de polícia sanitário em prol da saúde pública, com uma conotação de atuação substancial no caso concreto.

O elemento essencial da discussão circunscreve-se a verificar se as drogarias e farmácias podem disponibilizar em seus estabelecimentos e livremente

${ }^{4}$ BRASIL. Lei n. 8.080, de 19 de setembro de 1990. Dispõe sobre as condições para a promoção, proteção e recuperação da saúde, a organização e o funcionamento dos serviços correspondentes e dá outras providências. Disponível em: <http://www.planalto.gov.br/ccivil_03/leis/l8080.htm>. Acesso em: 30 set. 2014. ${ }^{5}$ SILVA, De Plácido. Vocabulário jurídico. 29. ed. Rio de Janeiro: Forense, 2012. p. 736. 
comercializar produtos dos mais diversos, sem autorização expressa para tal, ou se, evidentemente, dependem dessa autorização legal ou regulamentar para propiciar o comércio de objetos específicos e inespecíficos.

Como já nos manifestamos em momentos anteriores, nem tudo que não é proibido é permitido, pois, para essa autorização de conduta em questões sanitárias, há necessidade de que o ato em si não venha a causar mal à saúde pública, motivo pelo qual os princípios da precaução e do in dubio pro salute ganham fundamental importância.

Curiosamente, pondera-se que o principal argumento para a liberação da comercialização de produtos pelos estabelecimentos desenvolve-se de maneira equivocada acerca de eventual e imanente violação do princípio da legalidade - previsto no Artigo 5, inciso II, da Constituição Federal de $1988\left(\mathrm{CF} / 88^{6}\right)$, ao consignar que "ninguém será obrigado a fazer ou deixar de fazer alguma coisa senão em virtude de lei” -, uma vez que a tutela nos assuntos de saúde pública envolve todos os sujeitos em sua acepção coletiva, não podendo se restringir a direitos de índole individual, cujo raciocínio jurídico é diverso.

De outro lado, o pretenso direito de uma pessoa jurídica de vender produtos de maneira irrestrita objetiva eminentemente o lucro de seus negócios, relacionados intrinsecamente com a atividade econômica exercida pela empresa.

Assim, a salvaguarda do interesse coletivo deve prevalecer, visto que, além de se relacionar com direitos atinentes a seres humanos - e, por conseguinte, de maior envergadura do que os pertinentes a pessoas jurídicas -, é evidente que o direito subjacente ao lucro jamais poderá suplantar o inerente à saúde dos seres humanos em sua acepção individual e coletiva.

Nesse caso, a título de ilustração, podemos nos reportar a um exemplo utilizado em diversos processos em que defendemos os atos oriundos do órgão de fiscalização sanitária, quando exercíamos o cargo de Advogado Público de um município no interior do Estado de São Paulo. Naquela ocasião, utilizávamos a hipótese ilustrativa de um cidadão diabético que, ao ingressar em um estabelecimento farmacêutico sem responsável técnico, viesse a pedir diretamente ao atendente um medicamento para "curar" uma gripe ou resfriado. Baseado no conhecimento leigo, esse atendente poderia sugerir o uso do mel com própolis durante alguns dias ou algo do gênero, produto que estaria disponível à venda no estabelecimento. Diante desse fato, não precisamos enumerar os efeitos maléficos à saúde do mencionado cidadão, nem mesmo tecer maiores comentários sobre eventuais reflexos em seu atendimento pelo Sistema Único de Saúde (SUS) em decorrência do agravamento de sua doença no futuro, o que demonstra o interesse público presente na questão.

${ }^{6}$ BRASIL. Constituição da República Federativa do Brasil. Disponível em: <http://www.planalto.gov.br/ccivil_03/constituicao/constituicaocompilado.htm>. Acesso em: 30 set. 2014. 
Em um argumento defensivo, os proprietários de estabelecimentos farmacêuticos poderiam conjecturar que, nos supermercados, o mel é disponibilizado de maneira irrestrita, sem qualquer proibição de comercialização. Ocorre que sua destinação e seu uso pelos que buscam um supermercado possui uma conotação de alimento, enquanto que, ao ser disponibilizado em drogarias e farmácias, adquire um caráter medicamentoso essencial. Isso não significa que sua composição se altere, mas sim que a impressão que causa nos consumidores dos produtos é diversa, com implicações inerentes à preservação da boa-fé e da proteção dos direitos dos consumidores, em verdadeira interconexão entre ramos diversos dos direitos (direito sanitário e direito do consumidor).

Como bem salientado por Claudio Bonatto, na maioria das vezes, "a parte economicamente mais forte impõe à outra as condições da contratação, deixando-lhe apenas a alternativa entre 'pegar ou largar"'7.

Devido à condição de inferioridade dos consumidores que não se restringe ao aspecto econômico - pois, muitas vezes, ela engloba o acesso à informação e ao conhecimento do produto ou serviço -, cunhou-se o princípio protetivo do consumidor, resguardado no Artigo $5^{\circ}$, inciso XXXII, da Constituição de 1988, sendo oportuna a transcrição das ponderações do autor supracitado, no sentido de preservação da igualdade entre os contratantes: "Dessa análise deflui a razão da edição de estatutos de proteção ao consumidor, pois, sem dúvida, na sua relação com os agentes econômicos verifica-se uma flagrante desigualdade, no sentido do desconhecimento técnico e científico do consumidor, no que tange aos bens-da-vida colocados no mercado de consumo"s.

Da mesma forma, a boa-fé objetiva inerente às relações jurídicas deve permear as atividades relacionadas ao oferecimento de serviços e produtos de interesse à saúde pública, consistindo na "conduta normal e correta para as circunstâncias, seguindo o critério do razoável".

Ora, os indivíduos que procuram supermercados em geral objetivam adquirir alimentos dos mais variados tipos, enquanto aqueles que frequentam estabelecimentos farmacêuticos buscam produtos no intuito de recomposição da sua saúde, ou ainda, para prevenção de doenças por meio de produtos especializados, com finalidades medicamentosas ou de cunho diferenciado do conceito de mero alimento por possuírem propriedades específicas.

Dentro dessa concepção, as pessoas podem ser induzidas a adquirir produtos que, ao invés de propiciar uma melhora em suas condições de saúde, as prejudiquem

\footnotetext{
${ }^{7}$ BONATTO, Claudio. Código de defesa do consumidor: cláusulas abusivas nas relações contratuais de consumo. 2. ed. Porto Alegre: Livr. do Advogado, 2004. p. 29-30.

${ }^{8}$ Id. Ibid., p. 30.

${ }^{9}$ VENOSA. Sílvio de Salvo. Direito civil: parte geral. 11. ed. São Paulo: Saraiva, 2011. p. 384.
} 
indevidamente - situação muitas vezes potencializada pela ausência de responsáveis técnicos nesses estabelecimentos ou de funcionários suficientemente instruídos para impedir um equívoco que, em certas circunstâncias, poderia ser fatal para a integridade física e psíquica do ser humano.

Diversos princípios jurídicos interferem nessa relação, sendo que, diante do sistema da ponderação ou sopesamento dos valores envolvidos na discussão, o que prevalecerá no aparente conflito de tutela de direitos será sempre a vida humana. Portanto, entre a livre iniciativa ou concorrência e a preservação da saúde, esta última sagrar-se-á vitoriosa, com a preservação da saúde pública, pois a unidade da Constituição enseja a observância de suas disposições de maneira sistematizada e, em uma escala hierárquica de valores e direitos, em que a vida e a dignidade da pessoa humana são resguardadas em detrimento de direitos patrimoniais, o bem maior jamais perecerá.

Robert Alexy ressalta que "o objetivo desse sopeso é definir qual dos interesses - que abstratamente estão no mesmo nível - tem maior peso no caso

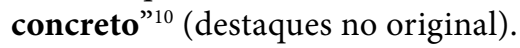

A vida (tutelada no caput do Artigo $5^{\circ} \mathrm{da} \mathrm{CF} / 88$ ), bem como a saúde (resguardada no caput do Artigo $6^{\circ} \mathrm{da} \mathrm{CF} / 88$ ), em interação conjugada com a dignidade da pessoa humana (prevista no inciso III do Artigo $1^{\circ} \mathrm{da} \mathrm{CF} / 88$, como um dos fundamentos da República Federativa do Brasil), não podem ser superadas pelo princípio da livre iniciativa (inserido no Artigo $170 \mathrm{da} \mathrm{CF} / 88$ como um dos elementos da ordem econômica), quando sua própria previsão no caput do dispositivo associa-o à garantia da "existência digna", com a necessidade de obediência aos preceitos de justiça social e de diversos princípios - que não se restringem à livre concorrência (inciso IV) -, mas pressupõe a defesa do consumidor (inciso V) e do meio ambiente, autorizando "tratamento diferenciado conforme o impacto ambiental dos produtos e serviços e de seus processos de elaboração e prestação" (inciso VI), dentre outras restrições que desconstituem qualquer pretensão de reputá-lo de índole absoluta.

Além disso, a Lei n. 5.991/1973 estabelece uma reserva de mercado para as farmácias e drogarias, conforme se depreende de seu Artigo $5^{\circ}$, ao estipular que "o comércio de drogas, medicamentos e de insumos farmacêuticos é privativo das empresas e dos estabelecimentos definidos nesta lei”.

A questão dos correlatos é elucidada pelo inciso IV, do Artigo $4^{\circ}$, Lei n. 5.991/1973, que os define como:

a substância, produto, aparelho ou acessório não enquadrado nos conceitos anteriores, cujo uso ou aplicação esteja ligado à defesa e proteção da saúde individual ou coletiva, à higiene pessoal ou

\footnotetext{
${ }^{10}$ ALEXY, Robert. Teoria dos direitos fundamentais. 2. ed. São Paulo: Malheiros Ed., 2012. p. 95.
} 
de ambientes, ou a fins diagnósticos e analíticos, os cosméticos e perfumes, e, ainda, os produtos dietéticos, óticos, de acústica médica, odontológicos e veterinários.

Da mesma forma, no parágrafo $1^{\circ}$ do Artigo $5^{\circ}$ do mesmo diploma, consigna-se que alguns produtos podem ser autorizados a serem comercializados por esses estabelecimentos, desde que correlatos, exemplificando com "aparelhos e acessórios, produtos utilizados para fins diagnósticos e analíticos, odontológicos, veterinários, de higiene pessoal ou de ambiente, cosméticos e perfumes, exercido por estabelecimentos especializados", condicionando, entretanto, que seja "observado o disposto em lei federal e na supletiva dos Estados, do Distrito Federal e dos Territórios".

Isso demonstra a autorização restrita de comércio nesses locais (farmácias e drogarias), pois o supermercado, nos termos da lei, deve ser reputado "estabelecimento que comercializa, mediante autosserviço, grande variedade de mercadorias, em especial produtos alimentícios em geral e produtos de higiene e limpeza", não sendo a ele permitida a disponibilização de medicamentos (Artigo 4º inciso XVIII, da Lei n. 5.991/1973).

Outra circunstância que referenda a conclusão acima delineada ocorre pela análise do disposto no parágrafo $2^{\circ}$ do Artigo $5^{\circ}$ do diploma legal em comento, uma vez que salienta que a "venda de produtos dietéticos será realizada nos estabelecimentos de dispensação e, desde que não contenham substâncias medicamentosas, pelos do comércio fixo".

"Dispensação", pelo teor do inciso XV do Artigo $4^{\circ}$ da mencionada lei, refere-se ao "ato de fornecimento ao consumidor de drogas, medicamentos, insumos farmacêuticos e correlatos, a título remunerado ou não", enquanto "produto dietético" deve ser entendido, conforme o inciso XVII, como "produto tecnicamente elaborado para atender às necessidades dietéticas de pessoas em condições fisiológicas especiais".

Assim, percebe-se que os supermercados não podem comercializar medicamentos, salvo se constituírem um estabelecimento farmacêutico independente, não se verificando no Brasil a livre disponibilização de produtos farmacêuticos em locais especializados no comércio de alimentos, como mercados ou lojas de conveniência.

As populares lojas de conveniência são definidas pelo inciso XX do Artigo $4^{\circ}$, Lei n. 5.991/1973, como:

Loja de conveniência e "drugstore" - estabelecimento que, mediante autosserviço ou não, comercializa diversas mercadorias, com ênfase para aquelas de primeira necessidade, dentre as quais alimentos em geral, produtos de higiene e limpeza e apetrechos domésticos, podendo funcionar em qualquer período do dia e da noite, inclusive nos domingos e feriados. 
Aproveitando essa discussão, podemos nos utilizar de outro exemplo para ilustrar problemas relacionados à disponibilização irrestrita de produtos nas farmácias e drogarias.

Imaginemos que, com a ampla autorização desejada, diante do argumento de ausência de proibição expressa, aproveite-se o estabelecimento farmacêutico para a venda de peixes e aves vivos ou abatidos para o consumo, ou ainda, transforme-se o local em um pet shop, com atendimento também a animais em conjunto com os seres humanos.

Em um primeiro momento, identifica-se que já seria difícil ao comerciante atender todas as normas sanitárias vigentes, visto que, para cada tipo de estabelecimento, existem solicitações diferenciadas para a viabilidade da concessão da licença de funcionamento pela vigilância sanitária.

Ainda que houvesse esse atendimento, o custo para a implementação das exigências sanitárias inviabilizaria o funcionamento de alguns estabelecimentos, sendo que, em virtude de alterações na legislação e da necessidade de readequação das estruturas e das boas práticas de armazenamento, atendimento e disponibilização, tais fatos causariam transtornos mais do que suficientes para impedir a recomendação da criação de tais locais.

Associado a isso, devemos ressaltar que o asseio que deve permear os estabelecimentos farmacêuticos não serve apenas para viabilizar a disponibilização de produtos em condições e padrões de qualidade legalmente aceitos aos consumidores, uma vez que são locais frequentados por pessoas muitas vezes acometidas de doenças graves e, portanto, com fragilidades físicas que, em certas circunstâncias, não podem ser submetidas a determinados ambientes.

De outro lado, ainda que os acometidos por doenças ou males dos mais variados pudessem livremente frequentar o local, a possibilidade de proliferação dessas doenças devido ao contato com os alimentos é facilmente perceptível e, muito provavelmente, potencializaria um risco desnecessário à saúde da população.

Nas questões relacionadas com a aplicação das normas sanitárias, não se deve observar apenas o conteúdo abstrato das disposições legais, pois o conhecimento técnico das diversas profissões associadas à área da saúde exerce influência e contribuição essenciais para a defesa dos cidadãos, o que deve ser ponderado pelos juristas na interpretação das disposições de índole sanitária.

Deve-se observar que esses preceitos de maior magnitude - tais como a vida, a segurança e a saúde do ser humano - por imperativo constitucional influenciam a interpretação das diversas normas permeadas pelo ordenamento jurídico, sendo propícia a transcrição da posição de Humberto Ávila:

(...). O ordenamento jurídico estabelece a realização de fins, a preservação de valores e a manutenção ou a busca de determinados 
bens jurídicos essenciais à realização daqueles fins e à preservação desses valores. O intérprete não pode desprezar esses pontos de partida. Exatamente por isso a atividade de interpretação traduz melhor uma atividade de reconstrução: o intérprete deve interpretar os dispositivos constitucionais de modo a explicitar suas versões de significado de acordo com os fins e os valores entremostrados na linguagem constitucional ${ }^{11}$.

Em virtude dessas ponderações, o legislador - sensível às dificuldades da proteção à saúde da população, que poderia ficar enrijecida com as demoradas alterações das leis em sentido estrito, por meio do processo legislativo ordinário resolveu criar a Anvisa, com poder normativo para editar regras de conteúdo obrigatório, por meio de resoluções de sua diretoria colegiada, o que possibilita uma mais rápida adequação das normas de salvaguarda às realidades e modificações sociais decorrentes dos avanços tecnológicos que interferem nas questões de saúde pública.

O próprio registro no Ministério da Saúde não deixa de ser uma exigência adotada em prol do interesse público, como expressão do exercício do poder de polícia estatal, no sentido de que a "polícia administrativa" nada mais é do que "a atividade da Administração de (nos termos da lei) delinear os contornos dos direitos assegurados pelo ordenamento, mas não é só: também a de compatibilizá-los com os demais valores que a ordem normativa assegura"12.

Como bem pondera Carlos Maximiliano: "Considera-se o Direito como uma ciência primariamente normativa ou finalística (5); por isso mesmo a sua interpretação há de ser, na essência, teleológica. O hermeneuta sempre terá em vista o fim da lei, o resultado que a mesma precisa atingir em sua atuação prática (...)"13.

Assim, conclui-se que a decisão proferida pelo Tribunal de Justiça de São Paulo foi bem lançada e, apesar de tratar especificamente de um caso concreto referente à impossibilidade de "livre comercialização de produtos cosméticos, assim como a sua manipulação, exposição, estoque mínimo”, com o intuito do autor de afastar eventual registro no Ministério da Saúde e outras exigências da fiscalização sanitária -, propicia a análise de diversos princípios, como o da precaução, do in dubio pro salute, da boa-fé e da proteção dos consumidores, bem como ressalta a importância dos conhecimentos inerentes às profissões relacionadas à área da saúde e do poder normativo da Anvisa para a proteção da saúde coletiva da população, pois, ainda que não se manifeste expressamente sobre a matéria, constata-se que os fundamentos externados derivam dessas ponderações de maneira reflexa, uma vez decorrerem do fim último da norma posta.

\footnotetext{
${ }^{11}$ ÁVILA, Humberto. Teoria dos princípios: da definição à aplicação dos princípios jurídicos. 14. ed. São Paulo: Malheiros Ed., 2013. p. 37-38.

${ }^{12}$ ARAÚJO, Edmir Netto de. Curso de direito administrativo. 5. ed. São Paulo: Saraiva, 2010. p. 1046.

${ }^{13}$ MAXIMILIANO, Carlos. Hermenêutica e aplicação do direito. 20. ed. Rio de Janeiro: Forense, 2011. p. 124-125.
} 
Os limites ao comércio de produtos farmacêuticos

\section{Referências}

ALEXY, Robert. Teoria dos direitos fundamentais. 2. ed. São Paulo: Malheiros Ed., 2012.

ARAÚJO, Edmir Netto de. Curso de direito administrativo. 5. ed. São Paulo: Saraiva, 2010.

ÁVILA, Humberto. Teoria dos princípios: da definição à aplicação dos princípios jurídicos. 14. ed. São Paulo: Malheiros Ed., 2013.

BONATTO, Claudio. Código de defesa do consumidor: cláusulas abusivas nas relações contratuais de consumo. 2. ed. Porto Alegre: Livr. do Advogado, 2004.

MAXIMILIANO, Carlos. Hermenêutica e aplicação do direito. 20. ed. Rio de Janeiro: Forense, 2011.

SILVA, De Plácido. Vocabulário jurídico. 29. ed. Rio de Janeiro: Forense, 2012.

VENOSA. Sílvio de Salvo. Direito civil: parte geral. 11. ed. São Paulo: Saraiva, 2011.

Luiz Henrique Sormani Barbugiani - Mestre em Direito pela Faculdade de Direito da Universidade de São Paulo; Pós-Graduado lato sensu em Direito Sanitário pela Faculdade de Saúde Pública da Universidade de São Paulo. Pós-Graduado lato sensu em Saúde Pública pela Universidade de Ribeirão Preto. Membro do Instituto Brasileiro de Advocacia Pública. Procurador do Estado do Paraná. Curitiba/PR, Brasil.E-mail: henrluiz@yahoo.com.br. 